Gazi University
Journal of Science
http://dergipark.gov.tr/gujs

\title{
Comparative Study Between a Battery and Super-capacitor of an Electrical Energy Storage System for a Traditional Vehicle
}

\author{
Majeed Rashid ZAIDAN ${ }^{1}$ (D) , Ghanim Thiab HASAN $^{2}$ (D) Mudhar A. AL-OBAIDI $^{1, *}$ \\ ${ }^{l}$ Middle Technical University, Technical Institute of Baquba, Baquba, Diyala - Iraq \\ ${ }^{2}$ Tikrit University, Oil and Minerals Engineering College, Tikrit - Iraq \\ Highlights \\ - Efficacy of lead battery was evaluated and compared versus ultra-capacitors and alternate battery. \\ - Several parameters were evaluated such as the weight and reliability. \\ - Lead-acid batteries are an appropriate replacement to super-capacitors.
}

Article Info

Received: 16 July 2021

Accepted: 01 Nov 2021

Keywords

Lead-acid batteries

Super-capacitor

Modelling

Simulation

Performance analysis

\begin{abstract}
Lead-acid batteries are widely used in the conventional cars as a main electrical energy storage system to supply the power for the following start. In this paper, the efficacy of lead batteries was evaluated and compared against ultra-capacitors and alternative battery designs via a simulationbased model of the complete process. Specifically, several parameters were assessed such as the weight and reliability. The results confirm the consistency of lead-acid batteries as an appropriate replacement to super-capacitors. The findings were also confirmed by actual measurements carried out in the car.
\end{abstract}

\section{INTRODUCTION}

Strong and affordable batteries represent a key challenge for hybrid vehicles. Hybrid electric vehicle batteries are characterized by its high-performance as they stand for a prolong operation time [1]. Specifically, connecting a battery pack to a super-capacitor provides a longer life, a higher charge/discharge speed and a lower internal resistor [2]. This in turn leads to a lower heat losses and improved reliability. Statistically, SC improves the efficiency of motor's cycling to approximately $95 \%$ compared to $85 \%$ of the factory's battery [3]. Therefore, the integrated battery and super-capacitor has been extensively applied as a hybrid energy system (HESS) compared to individual batteries [4]. Generally, the batteries can be integrated in vehicles in three stages: (1) single cell batteries, (2) single battery cell packs, and (3) battery module packs [5].

Lead-acid batteries have traditionally been used in traditional automobiles for more than 100 years due to their ruggedness and dependability [6]. These batteries are roughly suited for stationary (photovoltaic) applications as they are inexpensive [7]. However, the performance of lead-acid batteries needs to be improved as they are characterized by its low-life expectancy and specific energy density, which signify its disadvantages [8,9]. In this regard, Lee et al. and Castaings et al. [10,11] investigated the performance of lead-acid batteries and suggested the necessity of its improving. The main option for upgrading lead batteries was the use of sophisticated electrode technology materials. In these cases, the life span of the battery is generally extended by doping of the electrode with carbon or titanium dioxide [12]. Other 
improvement was made by substituting the lead-acid batteries with Li-Ion or Nickel-Metal Hydride (NiMH) cells that extensively used in hybrids and electrical cars [13]. These types of batteries are characterized by its efficient storage of energy and long-lasting.

More significantly, super-capacitors or electrical double-layer capacitors were used as a modern long-life technology to substitute the lead-acid storage batteries. Apparently, much interest has been paid in the use of novel materials such as notably nanotubes and graphite [14]. However, the major disadvantage of supercapacitors is that they only allow a single operation to be carried out. Therefore, combining a lead-acid battery and super-capacitors for synthesis and energy storing is one of the latest research options. Bi et al [14] confirmed the potential and successfulness of integrating lead battery and super-capacitors as the most cost-effective combination compared to lead-acid batteries. However, this technology is still under further improvement and needs an intensive research to be achieved. Expectedly, this would announce the advantages of this system and its preliminary contribution. It is important to mention that less than $1 \%$ of conventional vehicles were fitted with this hybrid system battery [15]. Up to the authors' knowledge, an intensive assessment of the hybrid system of lead-acid battery and super-capacitor has not been yet accomplished. Therefore, this research comes to enhance the performance of the hybrid lead-battery and super-capacitor system.

\section{BACKGROUND}

\subsection{Conventional Car}

The traditional car is a nonlinear system consisting of many subsystems with different degrees of nonlinearity. Internal Combustion Engine (ICE) is the central system, supported by twin electric motors and some converters (rectifiers). This seems to be a complicated approach, particularly for the ICE. Various non-linear features for the compression torque, the viscosity friction torque and coulomb friction moment [16] have appeared in the modeling of the diesel engine.

\subsection{Internal Combustion Engine (ICE)}

The modelling of ICE is an important and complicated task [17]. However, it might be modeled by a nonlinear circuit, as illustrated in Figure 1, in that the thyristor simulates starting of the ICE-powered machine and works uniformly after the first signal. The constant engine speed after start-up was simulated by constant current through the corresponding circuit.

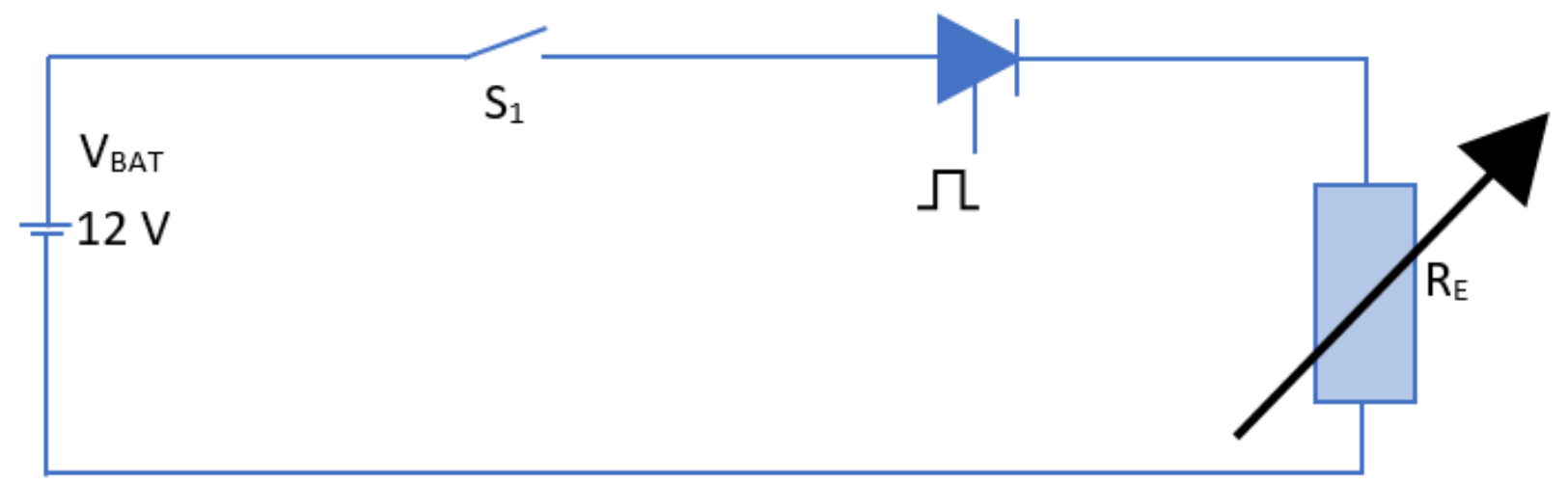

Figure 1. Simplified equivalent circuit of the ICE motor [17]

The circuit only flows despite the battery's positive voltage when switch S1 (ignition key) and thyristor are both turned on. This means that ICE only starts if the speed limit of $200 \mathrm{rpm}$ has not been reached. However, the thyristor will not conduct if the current is smaller (analogous to the speed of the motor). This is similar to the thyristor sustaining current. The internal combustion motor will generate constant torque once a thyristor starts to run for the production of power through an AC machine. Different speeds (or currents) of the motor can be reached by varying the accelerator pedal setting (or the resistance value RE). The motor 
can be switched off by turning off switch S1 or by increasing the RE load. Following a successful start, the machine with ICE will generate a constant moment for generator action.

\subsection{Electrical Starter Model}

The series-wound DC motor was primarily used for starting the internal engine. However, it was also possible to construct variations using magnets. The resulting torque $\mathrm{M}$ can be calculated from the product of the magnetic field and rotor current as indicated in Equation 1[18]

$M=K_{1} I_{A}^{2}$,

$\mathrm{M}$ and IA are the generated torque and current of the rotor, respectively.

For machines equipped with current-dependent (series-wound) magnetic fields or in the case of permanent magnets, the relationship between the torque M of the DC motor and the current of the rotor IA can be calculated as follows [18]

$M=K_{2} I_{A}$

$K_{1}$ and $K_{2}$ are constants. Although the direct current motor may not be a reliable solution, it has been used frequently due to its economic efficiency.

\subsection{The Generator}

In classic vehicles, the rotor is a synchronous machine with controlled magnetic fields (electromagnet). In order to keep the voltage induced under different operating states (various vehicle speeds) constant, the synchronous machine's circuit must be supported by a closed loop to the rotor circuit. This item uses a permanent magnet model. Therefore, a high-speed starting condition was simulated without analysis [19].

\section{THEORETICAL MODELS}

\subsection{Lead-acid Battery Model}

There are several models of batteries, including either a single resistor and capacitor or two resistance elements and two capacities (two-pair RC model) [20]. These models can be efficiently used for simple comparison of cells with super-capacitors. However, subsequent modeling for long-term durability and other long-term parameters requires precise measurements. Figure 2 illustrates the block diagrams for a lead battery connected to a load.

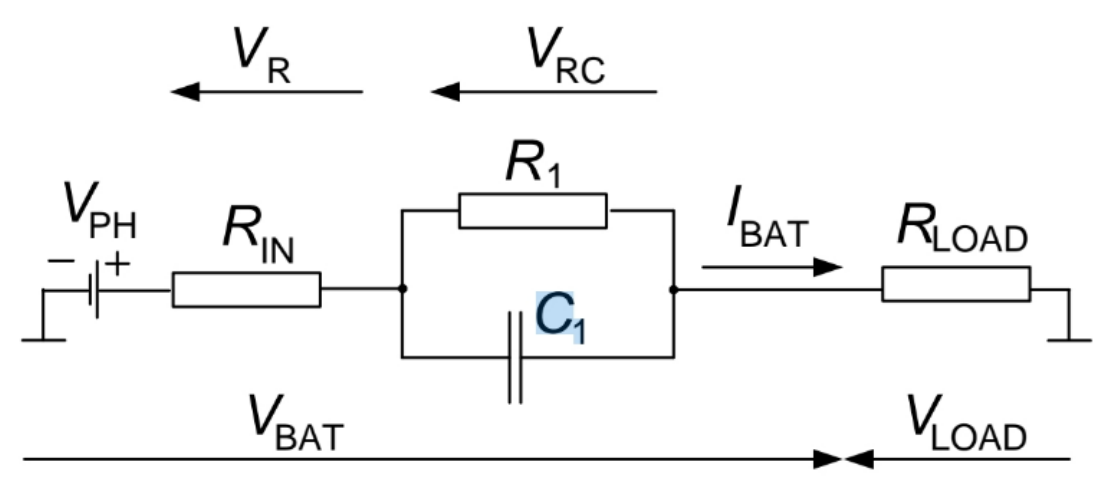

Figure 2. Block diagram of lead battery connected to load [20]

According to Figure 2, the voltage of the lead-acid battery is expressed in the following equation

$V_{B A T}=V_{P H}+V_{R}+V_{R C}=V_{P H}+R_{I N} I_{B A T}+V_{R C}$. 


\subsection{The Super-capacitor}

Super-capacitor has a simple design compared to battery. However, charging and discharging characteristics are associated with determining their life span. Generally, super-capacitors constitute a capacitor and a resistance connected in series as depicted in Figure 3.

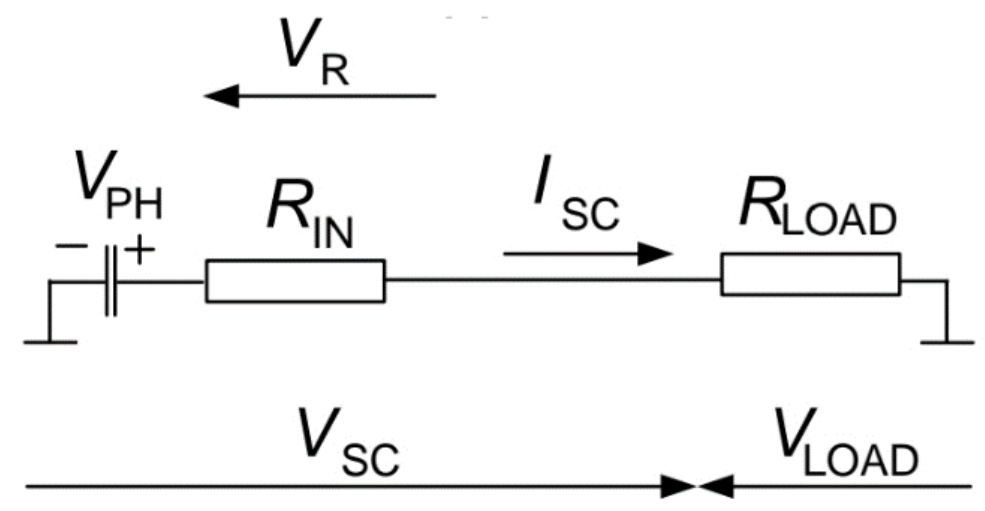

Figure 3. Schematic diagram of the super-capacitor connected to load [20]

In short-time tests, a self-discharge resistor can be neglected. Therefore, the voltage of super-capacitor is expressed as

$V_{S C}=V_{P H}+V_{R}=V_{P H}+R_{I N} I_{S C}$.

The pattern shown in Figure 3 has been considered in the simulation of start-up, which takes up to 2 seconds. When testing super-capacitors, it has been found that the super-capacitors discharge after a number of hours. For the longer tests, additional resistance has been added to the circuits, as shown in Figure 2.

\section{SIMULATION OF A CONVENTIONAL VEHICLE}

In order to balance super-capacitors that are connected together in series, they have to be paralleled connected with additional resistors or other voltage equalization devices in order to prevent voltage unevenness at certain super-capacitors. Simulation elements have been taken from data sheets and test works or directly from the measurement on the commercial vehicle.

A simple model of a car was modeled in order to simulate the bend of the conventional car with different storage devices. The simulation based model is starting a vehicle in the car park. Practical results were then obtained to validate the simulation findings. The diagrammatic representation of a conventional car to simulate multiple energy storage devices when starting the car is shown in Figure 4.

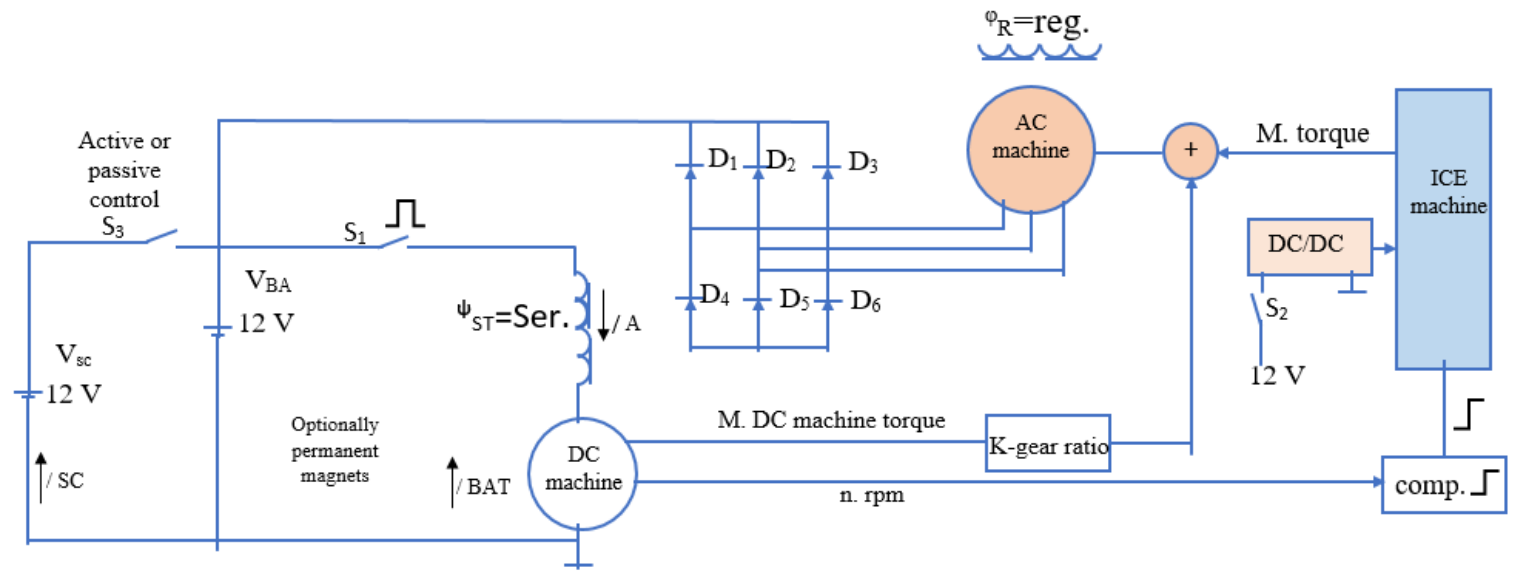

Figure 4. Schematic diagram of the conventional vehicle for simulating several energy storing systems during start-up [20] 


\section{RESULTS AND DISCUSSION}

The car starting simulation plays a key role in studying several interactions, such as the dependence of starting current on engine temperature, Enhanced Machine Controller (EMC) interference, etc. It seems that the batteries allow successful starting at a voltage of $12 \mathrm{~V}$ (Figures 5 and 8), but super-capacitors do not allow successful starting because of the rapid discharge and increased voltage drop on starting, as shown in Figures 5, 6, 7 and 8.

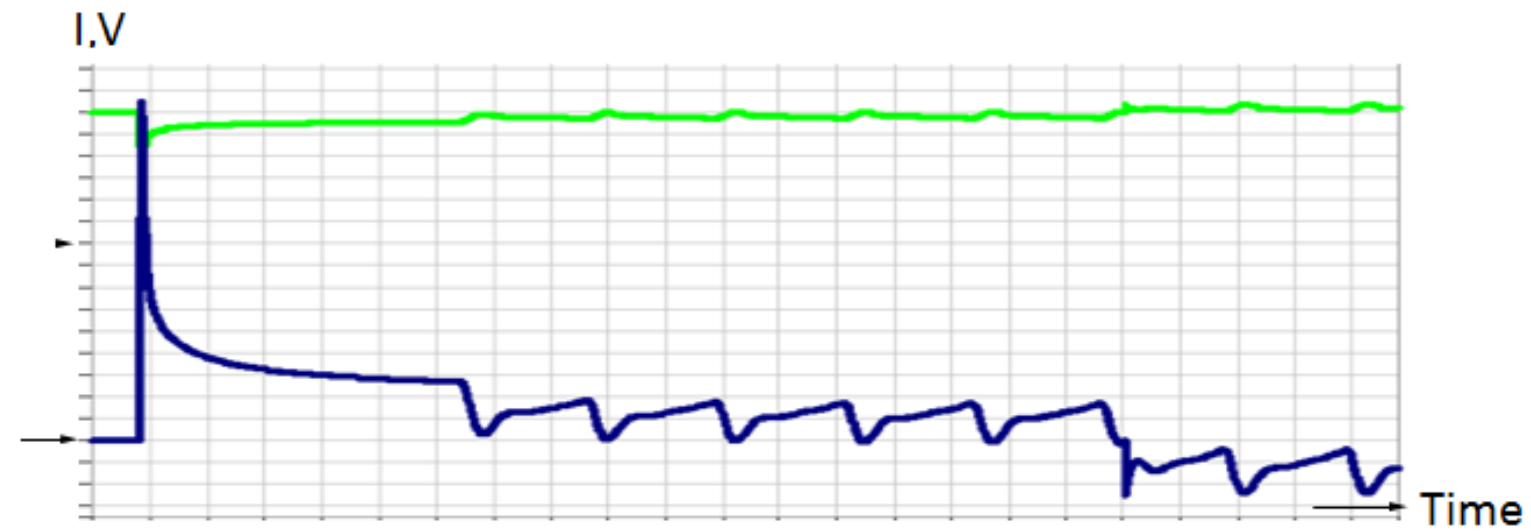

Figure 5. Simulation of the waveforms of DC link voltage and storage system current during starting (lead acid battery for successful)

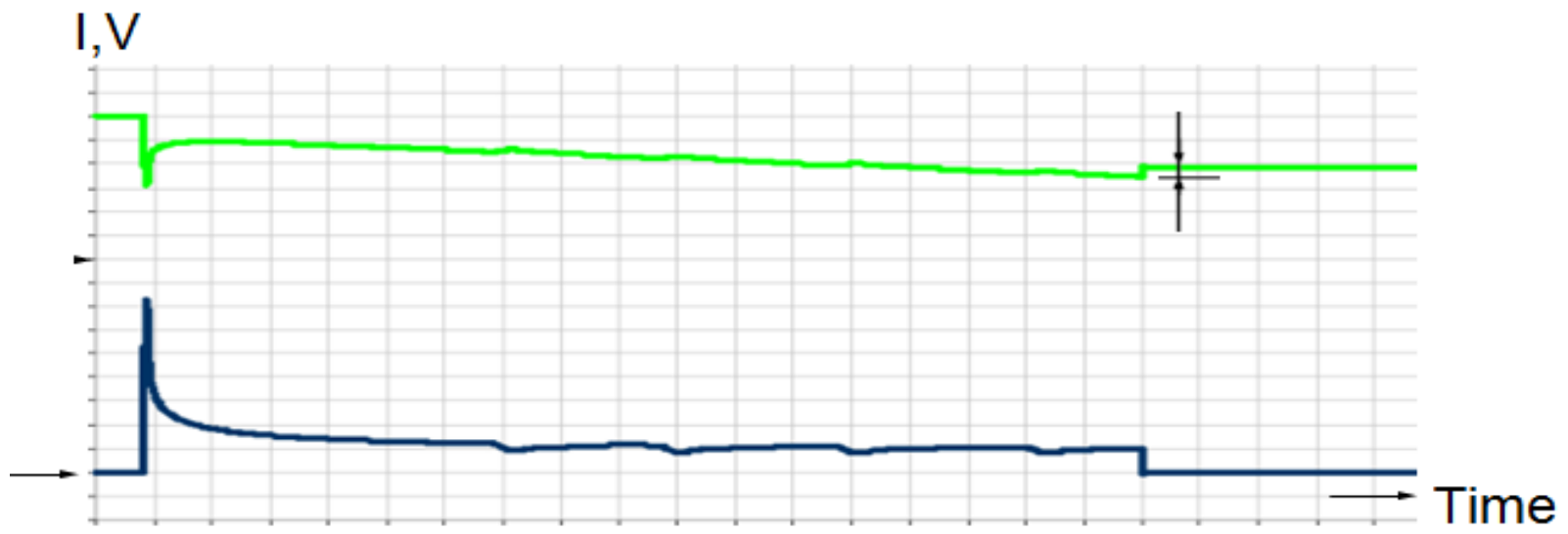

Figure 6. Simulation of waveforms of the DC link voltage and current of the energy storage system during start-up (super-capacitor of a failed start-up (25 A/div., 2 V/div., $100 \mathrm{~ms} /$ div.)) 


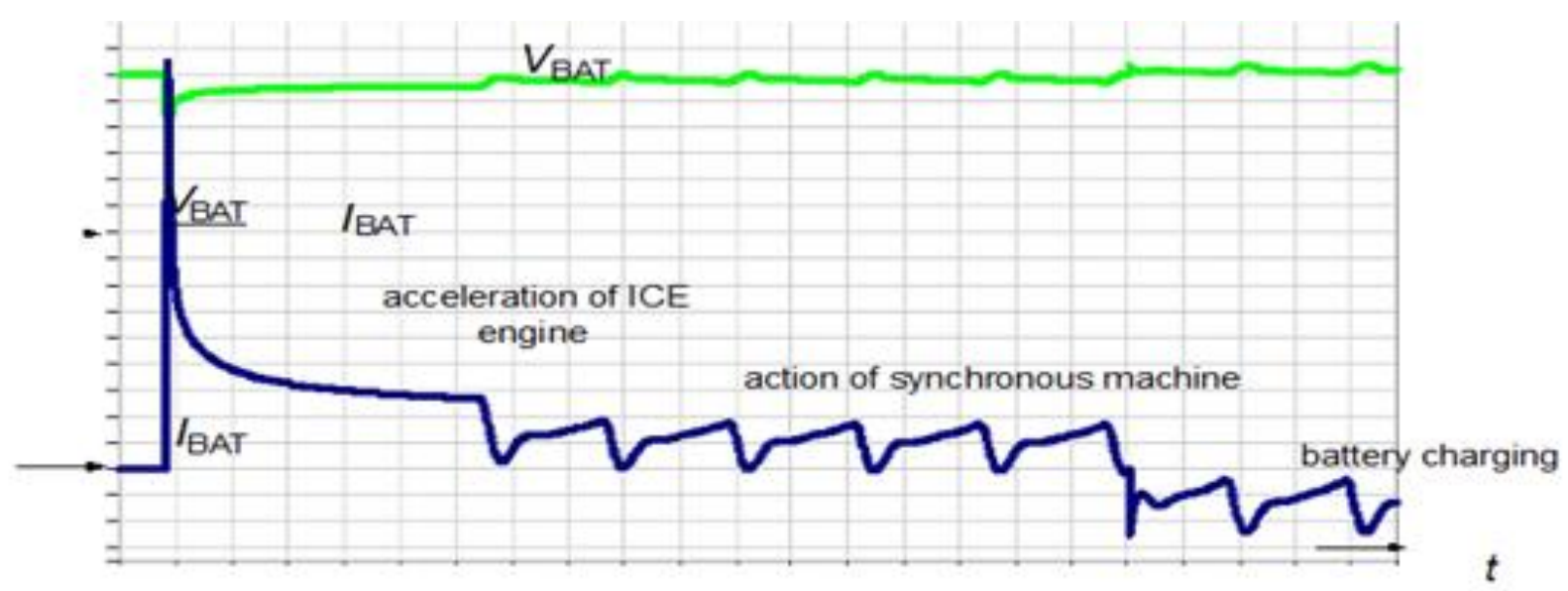

Figure 7. Measured DC link voltage (green line) and energy storage system current (blue line) ripple patterns during startup (super-capacitor failed)

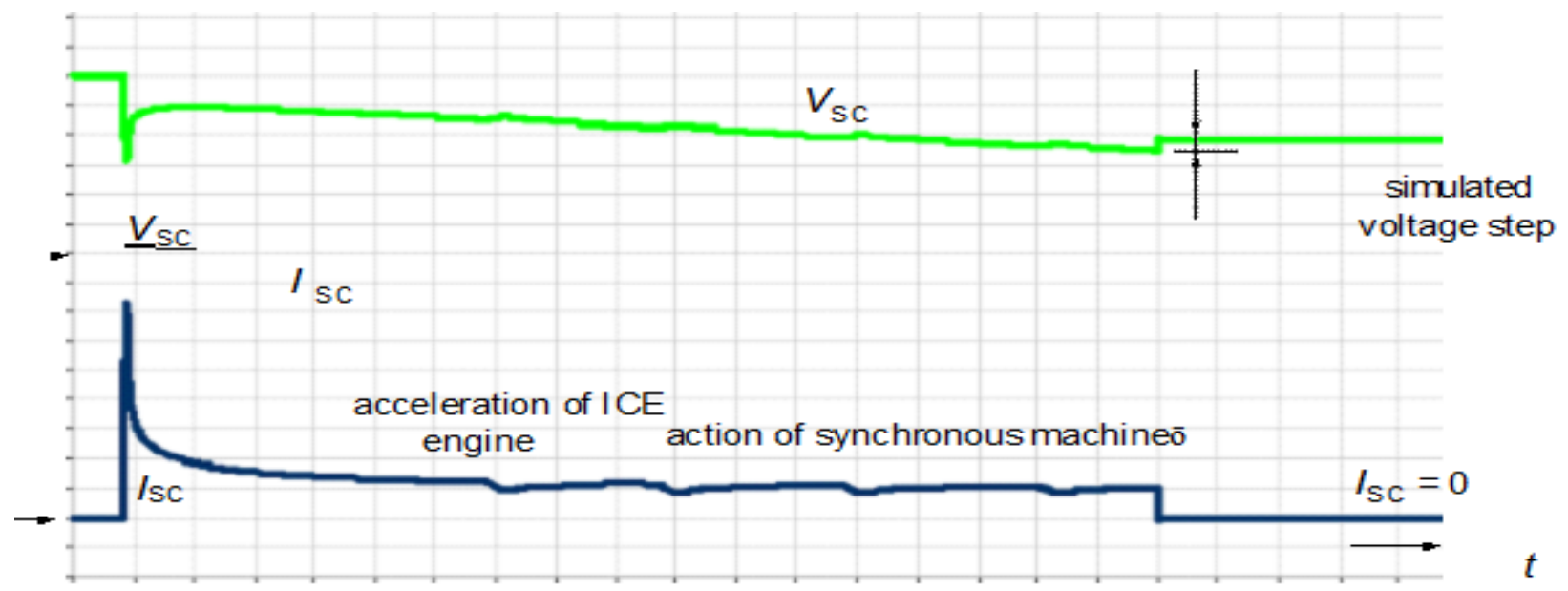

Figure 8. Start-up of lead storage batteries using Li ion batteries and start-up of electrolytic condensers [( successful startup with super-capacitors (100 A/div., 5 V/div., $500 \mathrm{~ms} /$ div.)]

This situation can be modified through increasing the capacity of super-capacitors. Capacitance fitting in a simulator model is easily done, however, practical considerations have been made for a capacitance value of series-connected super-capacitors having a combined capacitance of $\mathrm{C}=66.7 \mathrm{~F}$. This is specifically corresponding to a series arrangement of a maximum of six super-capacitors $(\mathrm{CSC}=400 \mathrm{~F}, 2.7 \mathrm{~V})$. As the simulations enable the capacity values to vary, it can be precisely defined or simulated a boundary between a successful and unsuccessful start.

The experimental measurements of the simulation results are given in Figure 9. However, it appears that the simulations are more flexible and allow various adjustments. It was chosen that starting takes about 0.7 seconds and various tests under identical conditions. Such an exact adaptation of test conditions is impossible with experiments. For instance, temperature was not considered in the model simulated, but a hotter ICE requires less energy for starting compared to an engine at outdoor temperature. That is, after a few minutes of running, the ICE has approximately 100 amperes (25\%) fewer current peaks during commissioning. In any case, the torque of an ICE motor is non-constant, and vibrations will occur during experimental tests. The EMC interference of the direct current motor (starter) is another example of a nonlinearity that has not been accurately modelled. The measurement experiment is different in many details from simulation, but current and DC waveforms are practically unchanged during successful tests as well as simulations. In addition, it has been simulated that starting with $12 \mathrm{~V}, 20 \mathrm{~F}$ loaded super-capacitors at $0.7 \mathrm{~s}$ or at $0.9 \mathrm{~s}$ starting range is unsuccessful. However, an increase in capacitance up to $60 \mathrm{~F}$ or more leads 
to a successful start. In this manner, simulation was developed as a high-performance tool to enhance the performance of start-up and energy storing systems.

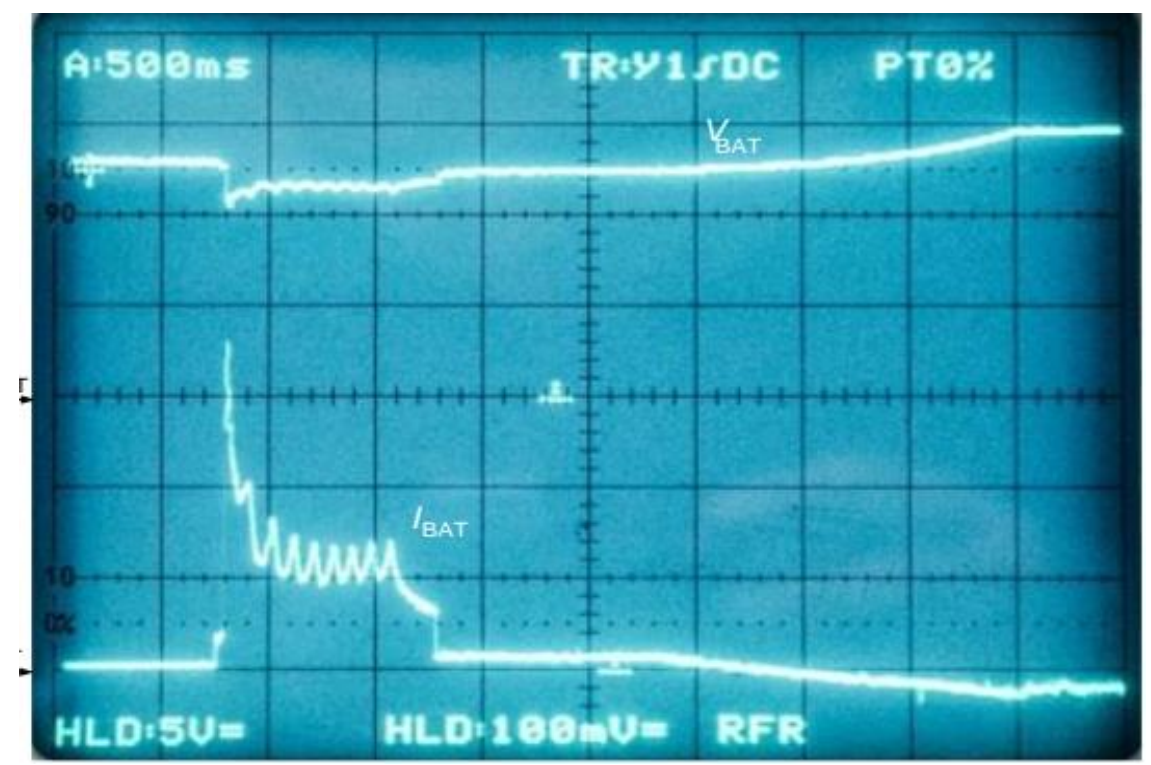

Figure 9. Measured Waveforms of DC link voltage and current of the energy storing system during the start (lead-acid battery startup)

Basically, car allows the exchange of one $12 \mathrm{~V}$ lead acid battery. Its weight is about $10 \mathrm{~kg}$ and its capacity about three litres, therefore many other energy storage systems can substitute lead batteries. Combinations with genuine lead-acid batteries are possible as well. By addition of another energy storage system, the drop in voltage is decreased during charging and discharging of the energy storage system, as shown in Figures 10 and 11. However, this approach is not cost-efficient, but could extend the lifetime of the whole system. Independent start only with Li-Ion or NiMH batteries has not been successful, because costeffective batteries with low power densities and a near AA size were used four series Li-Ion 3.7V; 9.62Wh; 2.6Ah or 12. Thus, super-capacitors alone can be used, as seen in Figure 12, providing a permanent, lightweight solution that is desirable in automotive applications. It seems, however, that super-capacitors have higher internal resistance compared to lead batteries, but the actual disadvantage is their lower nominal output voltage (typically $2.7 \mathrm{~V}$ ), which implies that a high number of super-capacitors have to be connected in series in order to solve these problems. There are many components in such a nonlinear system, which could have a comparable effect on startup. The degradation of the battery power was associated with the deterioration of the direct current machine.

Finally, the starter magnets were displaced, resulting in an irreversible damage of the rotor windings. Reliability of the system could be enhanced by the use of brushless or reluctant machines. Thus, a separate machine could be used in place of a DC or AC machine, as shown in Figure 4. In this regard, a single machine may be used instead of DC and AC machines, as shown in Figure 4. Furthermore, a microcontroller with low core could be used for active control of the switch S3. In this manner, the super-capacitor can only be used during startup without self-discharge, which might discharge the super-capacitor in just a few hours. 


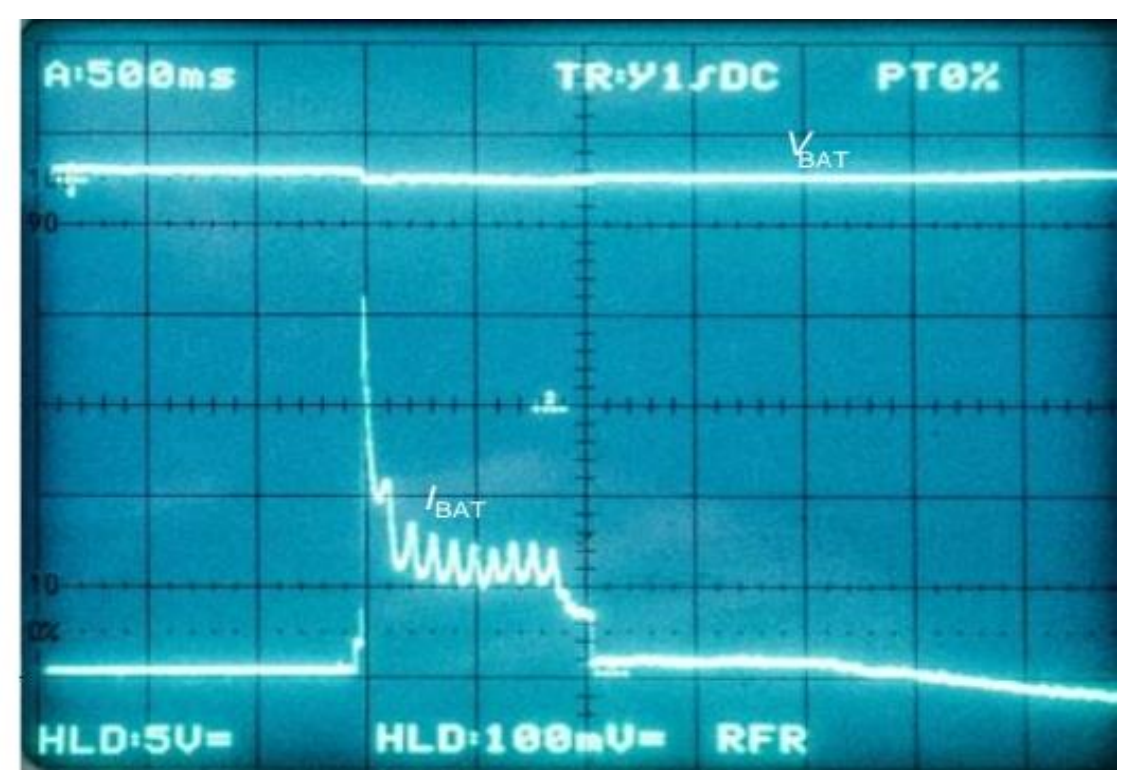

Figure 10. Measured curves of the DC intermediate voltage and current of the power storage systems during start-up (lead-acid battery with Li-ion) and electrolytic capacitors during starting

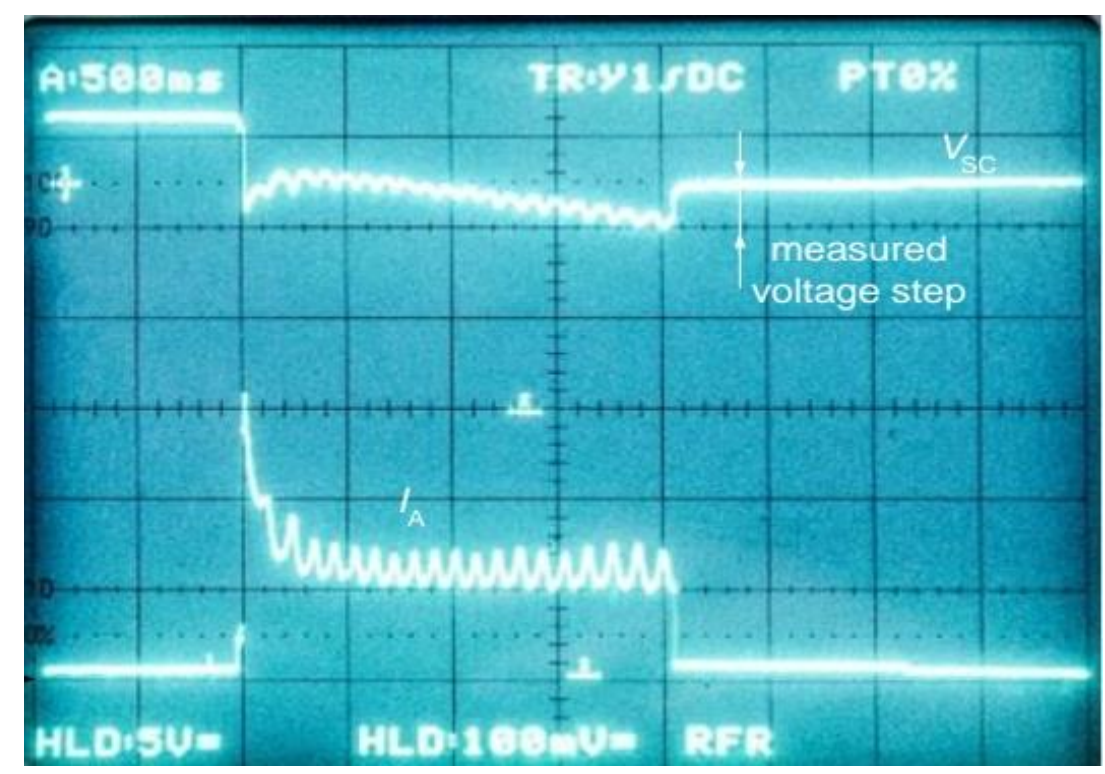

Figure 11. Measured curves of the intermediate circuit voltage and current of the energy storing system during start (super-capacitors unsuccessful start-up) 


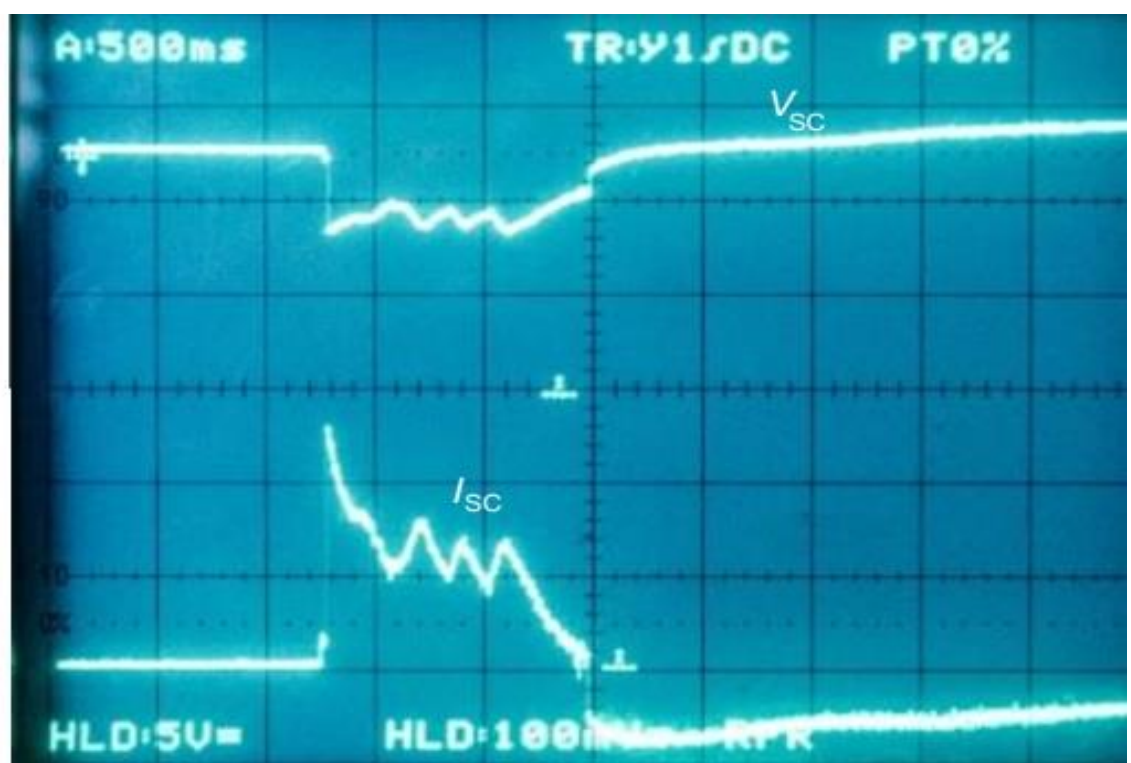

Figure12. Measured wave forms of DC link voltage and current of energy storage system during start-up (successful start-up using supercapacitors (100 A/div., 5 V/div., $500 \mathrm{~ms} / d i v$.

\section{CONCLUSIONS}

This paper focused on evaluating the efficiency of lead batteries using a simulation-based model and compared against ultra-capacitors and alternative battery. The Internal Combustion Engine (ICE) has been simulated by a Thyristor circuit, where a thyristor gate was used to simulate starting the vehicle and then uniform use. Simulations for the different storage battery systems using lead batteries as well as supercapacitors were also considered. Lead-acid batteries are durable storage systems which have proven themselves over many decades of successful operation. However, the starting of the lead-acid battery is much more dependably, as several tests can be carried out. Lead-acid batteries are far heavier compared to super-capacitors, so a parallel connection of lead-acid battery and super-capacitors should be considered for the mass production in the automobile industry. In this case, a reduction in the mass of the energy storage systems (approx. 50\%) can be anticipated with simultaneous extension of the life span. The results confirmed an improvement of the energy storage without any influence on the starting ability. Furthermore, the simulation models discover several aspects of interaction compared to real-life measurements with constraints regarding measuring devices and the restricted availability of specific components in the commercial vehicle.

\section{CONFLICTS OF INTEREST}

No conflict of interest was declared by the authors.

\section{REFERENCES}

[1] Yao, F., Geng, L., Janabi, A., Wang, B., "Impact of modulation schemes on DC-link capacitor of VSI in HEV applications", In: IEEE International Electric Machines and Drives Conference (IEMDC), (2017).

[2] Ruan, J., Walker, P.D., Watterson, P.A., Zhang, N., "The dynamic performance and economic benefit of a blended braking system in a multi-speed battery electric vehicle", Applied Energy, 183: 1240-58, (2016).

[3] Teixeira, A.C.R., Sodré, J.R., "Simulation of the impacts on carbon dioxide emissions from replacement of a conventional Brazilian taxi fleet by electric vehicles", Energy, 115: Part, 161722, (2016). 
[4] Ruan, J., Walker, P., Zhang, N.A., "Comparative study energy consumption and costs of battery electric vehicle transmissions", Applied Energy, 165: 119-34, (2016).

[5] Denis, N., Dubois, M.R., Trovao, J.P.F., Desrochers, A., "Power split strategy optimization of a plug-in parallel hybrid electric vehicle", IEEE Transactions on Vehicular Technology, 67(1): 315326, (2018).

[6] Badodkar, D.N., "Transient analysis of three-phase high- power voltage source inverter with nonlinearities in hybrid electric vehicles", IEEE Transactions on Power Electronics, 33(4): 36723680, (2018).

[7] Ruan, J., Walker, P., Zhang, N., "A comparative study energy consumption and costs of battery electric vehicle transmissions", Applied Energy, 165: 119-34, (2016).

[8] Song, Z., Hou, J., Hofmann, H, Li J., Ouyang, M., "Sliding-mode and Lyapunov function-based control for battery/supercapacitor hybrid energy storage system used in electric vehicles", Energy, 122: 601-12, (2017).

[9] Walker, P.D., Roser, H., Zhang, N., Fang, Y., "Comparison of Powertrain System Configurations for Electric Passenger Vehicles”, (2015). DOI:10.4271/2015-01-0052

[10] Lee, J., Jang, H., Shin, S., Jang, K., Jung, J., “Over temperature protection in power module for hybrid and electric vehicle", In 2016 IEEE Transportation Electrification Conference and Expo, Asia-Pacific (ITEC Asia-Pacific), IEEE, 432-435, (2016).

[11] Castaings, A., Lhomme, W., Trigui, R., Bouscayrol, A., "Comparison of energy management strategies of a battery/supercapacitors system for electric vehicle under real-time constraints", Applied Energy, 163: 190-200, (2016).

[12] Department for Transport UK Road Traffic Estimates: Great Britain (2015). Access date: 15.05.2020

[13] Saxena, S., MacDonald, J., Moura, S., "Charging ahead on the transition to electric vehicles with standard 120 V wall outlets", Applied Energy, 157: 720-8, (2014).

[14] Bi, Z., Song, L., De Kleine, R., Mi, C.C., Keoleian, G.A., "Plug-in vs. wireless charging: life cycle energy and greenhouse gas emissions for an electric bus system", Applied Energy, 146: 11-9, (2015).

[15] Moon, A., "Analysis of boost converter and interleaved converter for permanent magnet synchronous motor of hybrid electrical vehicle", In: International conference on electrical, electronics, and optimization techniques (ICEEOT), 4298-4303, (2016).

[16] Omar, N., Monem, M.A., Firouz, Y., Salminen, J., Smekens, J., Hegazy, O., "Lithium iron phosphate based battery - Assessment of the aging parameters and development of cycle life model”, Applied Energy, 113: 1575-85, (2014).

[17] Wu, Y., Keil, P., Schuster, S.F., Jossen, A., "Impact of Temperature and Discharge Rate on the Aging of a LiCoO 2 /LiNi 0.8 Co 0.15 Al 0.05 O2 Lithium-Ion Pouch Cell”, Journal of The Electrochemical Society, 164(7): A1438-45, (2017).

[18] Cherry, J., Merichko, T., "Battery durability in electrified vehicle applications: a review of degradation mechanisms and durability testing", Prepared for Environmental Protection Agency: Ann Arbor, MI, USA (2015). 
[19] Senanayake, T., Iijima, R., Isobe, T., Tadano, H., "Z-source with rectangular wave modulation inverter for Hybrid/Electric vehicles", In: 18th European conference on power electronics and applications (EPE'16 ECCE Europe), IEEE, 1-10, (2016).

[20] Li, X., Shamsi, P., "Inductance surface learning for model predictive current control of switched reluctance motors", IEEE Transactions on Transportation Electrification, 1(3): 287-297, (2015). 